\title{
A Química da Cerveja
}

\author{
MANUEL PEREIRA GALVÃO *
}

Sumariamente, a cerveja pode ser definida como uma bebida alcoólica, produzida quando o mosto, um extracto aquoso de malte e lúpulos, é metabolisado fermentativamente por leveduras. Esta poderia ser uma definição de cerveja retirada de qualquer dicionário. Parece um processo simples, não é? Na realidade a produção de cerveja envolve hoje em dia um entendimento profundo da química e bioquímica das matérias primas, da levedura e de todas as variáveis de um complexo mas fascinante processo. Só assim é possível proporcionar aos consumidores uma tão grande diversidade de cervejas com diferentes aromas e gostos como a que existe por todo o mundo onde esta bebida é consumida. A ciência e tecnologia cervejeiras cobrem um leque vasto de disciplinas como a microbiologia, a bioquímica, a genética, a fisiologia microbiana e a química. É dificil identificar todos os constituintes responsáveis pelo gosto e aroma, ou seja pelas características organolépticas da cerveja. Ao longo dos anos têm sido caracterizadas várias vias de síntese química e bioquímica que levam à formação da maioria dos compostos capazes de estimular os receptores nervosos que se encontram nas cavidades bucal e nasal dos humanos e provocar as sensações que normalmente temos quando bebemos uma cerveja. Cerca de 800 compostos diferentes são actualmente conhecidos na cerveja, sendo o seu contributo para as características globais da bebida variável.

O cervejeiro procura com os conhecimentos actualmente disponíveis condicionar ou estimular a produção desses compostos com o objectivo de produzir uma bebida com características próprias, que agrade aos consumidores, com uma qualidade regular e que se mantenha inalterada ao longo do tempo. Isso é conseguido por uma criteriosa escolha das matérias primas (água, malte e lúpulo), das estirpes de leveduras utilizadas e pela parametrização e controlo das inúmeras variáveis do processo produtivo.

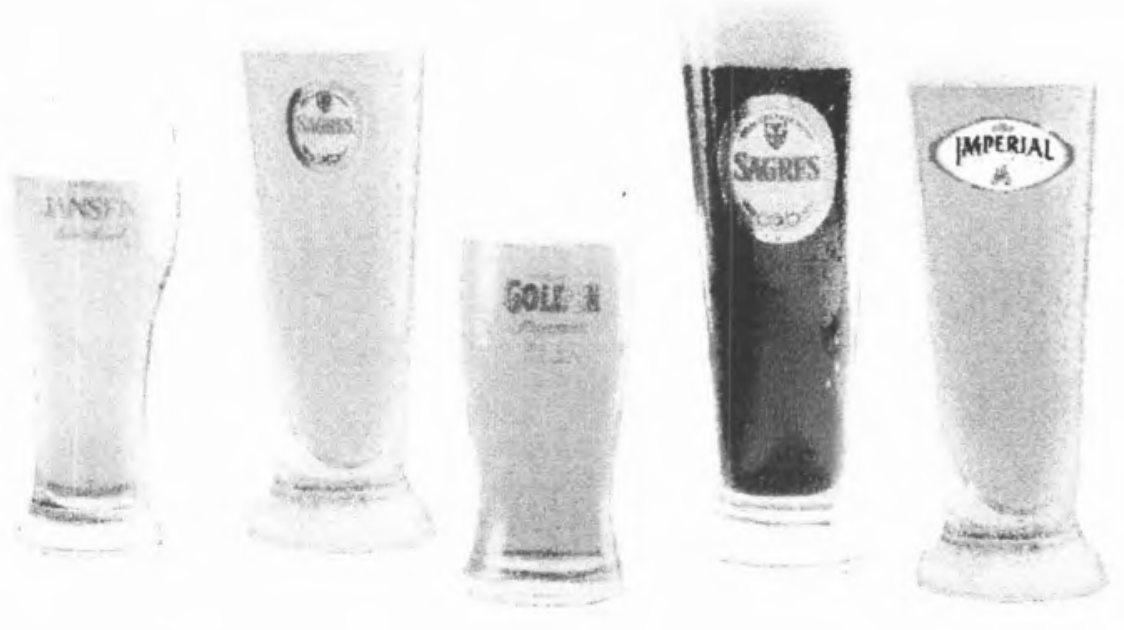

\section{A IMPORTÂNCIA DAS MATÉRIAS PRIMAS}

\section{A ÁGUA}

A água é o principal componente da cerveja (aproximadamente $93 \%$ ). É ela o suporte das combinações mais ou menos harmoniosas de todos os compostos químicos presentes nesta bebida. As características físico-químicas da água influenciam propriedades da cerveja como o aroma, o gosto, a limpidez, a cor e a espuma. Foi a qualidade da água utilizada na produção de cerveja que tornou famosas algumas cidades ou locais como Pilsen, Burton-on-Trent, Dortmund, Munique, e Viena. A água utilizada na produção de cerveja deve fornecer apenas alguns minerais úteis para o processo e deve ser desprovida de matéria orgânica e contaminação microbiológica. A presença de alguns iões na água é relevante para as características da cerveja produzida. $\mathrm{O}$ sulfato, $\mathrm{SO}_{4}{ }^{2-}$, por exemplo contribui para um gosto seco e amargo, enquanto que o ião cloreto, $\mathrm{Cl}^{-}$, acima de determinado nível confere um gosto adocicado e mais encorpado. O excesso de sulfatos pode também influenciar a quantidade de compostos voláteis sulfurados produzidos durante a fermentação, como o $\mathrm{H}_{2} \mathrm{~S}$ e o $\mathrm{SO}_{2}$.

Alguns iões derivados do ferro, conferem à cerveja um gosto metáli- co, quando existem em teores superiores ao recomendado. No entanto, os iões férrico e ferroso estão envolvidos na formação de compostos que conferem cor à cerveja e alguns sais de ferro têm uma influência positiva na espuma, embora lhe possam por vezes conferir uma cor acastanhada.

A água pode também influenciar indirectamente as caracteristicas da cerveja. O pH tem extrema importancia na modulação da actividade de certos enzimas presentes no malte, e no grau de extracção de vários compostos presentes no malte e no lúpulo, durante a primeira etapa do processo produtivo, a produção do mosto.

O MALTE

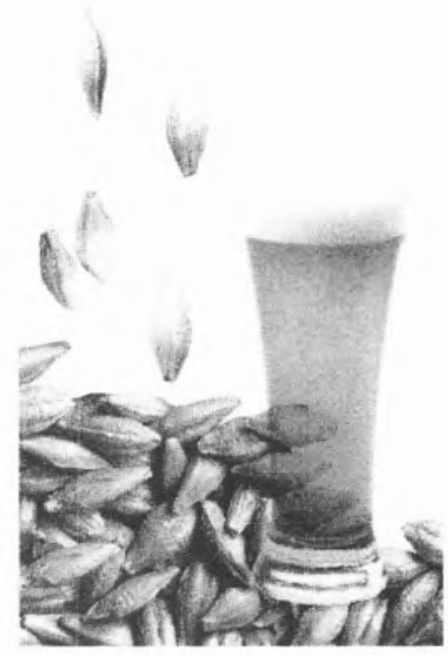




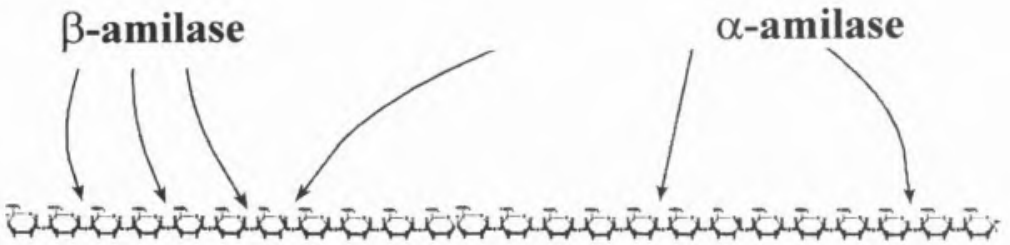

Molécula de amilose - resíduos de glucose ligados por ligações $\alpha-1,4$

O malte, cevada maltada é a principal fonte de substâncias quimicas com actividade sensorial (gustativa ou olfactiva), encontradas na cerveja, seja por via directa seja através das transformações que ocorrem durante a produção do mosto e a fermentação. No malte encontram-se uma multitude de compostos que incluem ácidos gordos voláteis, furanos, aldeídos, cetonas, fenóis, proteínas, glícidos, compostos sulfurosos, melanoidinas, polipéptidos e polifenóis. Alguns destes compostos desaparecerão enquanto outros irão sofrer modificações durante o processo cervejeiro. Essas modificações podem ser químicas, como por exemplo a oxidação ou a degradação térmica; ou bioquímicas, pela actuação da levedura.

A fracção glicídica é a predominante na constituição do malte. Durante a produção de mosto, as moléculas de amido presentes no malte são hidrolizadas enzimáticamente e transformadas em polissacarídeos, trissacarídeos, dissacarídeos e oses. Os primeiros sobrevivem até ao produto final, sendo os principais responsáveis pela viscosidade e densidade da cerveja, propriedades que se relacionam com o "corpo" da bebida. Os restantes glicidos, de menor grau de polimerização são metabolisados pela levedura durante a fermentação em complexas vias de catabolismo e de anabolismo.

Um exemplo importante de transformação química de um composto presente no malte é a formação do dimetilsulfureto (DMS) pela degradação térmica do aminoácido S-metilmetionina (SMM). O DMS é um composto sulfurado que se estiver presente na cerveja em concen- trações superiores a 30-40 ppb pode conferir-lhe um aroma bastante desagradável.

As proteínas presentes no malte têm extrema importancia, pela fonte de compostos azotados que constituem, essencial à boa performance fermentativa das leveduras e também pelo aporte enzimático fundamental na fase de produção do mosto. Os polipéptidos são um dos principais constituintes da espuma da cerveja, ao serem adsorvidos à superfície das bolhas de $\mathrm{CO}_{2}$ que se libertam no copo. Os aminoácidos participam na formação de compostos responsáveis pela cor da cerveja- as melanoidinas- que se formam pela reacção dos primeiros com açúcares, pela acção do calor. Estas reacções receberam o nome do químico que primeiro identificou as melanoidinas- Maillard.

A fracção lípidica do malte (cerca de 3\% da sua matéria seca) não é, na sua maior parte, solubiliza- da durante a fabricação do mosto. No entanto, a porção solubilizada constitui também uma potencial fonte de compostos organolepticamente activos. Alguns destes compostos podem posteriormente dar origem a produtos responsáveis pela degradação do sabor e aroma da cerveja ao longo do tempo. Nesta fracção, são importantes na velocidade da fermentação e no equilíbrio entre os compostos aromáticos das famílias dos álcoois e dos ésteres, os ácidos gordos de cadeia longa (palmítico, esteárico, oleico e linoleico).

\section{O LUPULO}

Desde os primórdios da produção de cerveja que se utilizam especiarias e plantas aromáticas para introduzir aromas especiais nesta bebida. Destas plantas, apenas o lúpulo (Humulus lupulos L.) é utilizado hoje em dia, numa escala comercial.

O lúpulo é uma planta da familia das Cannabinaceae. Apenas as plantas femininas do Lúpulo produzem as inflorescências, designadas por cones, utilizados na industria cervejeira. É a partir destes cones que é extraída a fracção resinosa onde se encontram os compostos que irão conferir o gosto amargo à cerveja, os ácidos $\alpha$. Este grupo de compostos sofre uma isomerização

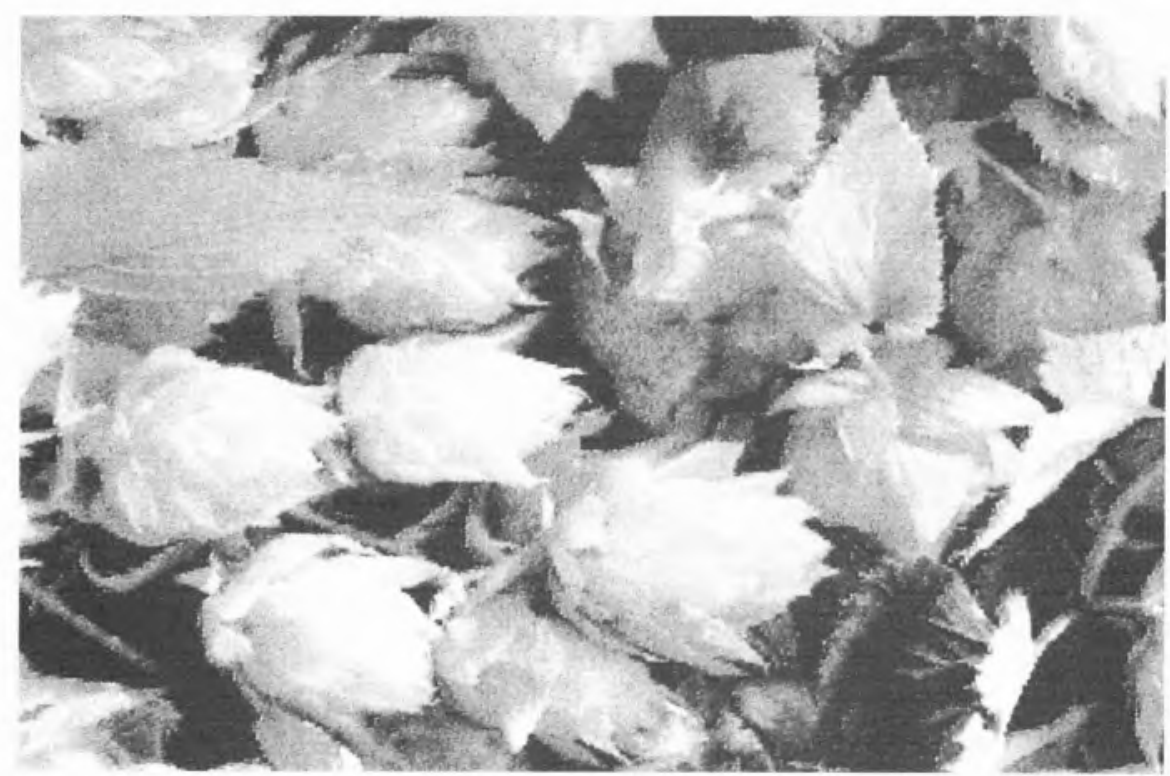


durante a fase final da produção do mosto, a ebulição, que os converte nos iso- $\alpha$-ácidos, que são muito mais amargos que os correspondentes áci$\operatorname{dos} \alpha$.

\section{Ácidos $\alpha$ (humulonas)}

$$
\begin{aligned}
\mathrm{R}= & -\mathrm{CH}_{2} \mathrm{CH}\left(\mathrm{CH}_{3}\right)_{2}-\text { humulona } \\
& -\mathrm{CH}\left(\mathrm{CH}_{3}\right)_{2}-\text { cohumulona } \\
& -\mathrm{CHCH}_{3} \mathrm{CH}_{2} \mathrm{CH}_{3} \text { - adhumolona }
\end{aligned}
$$<smiles>[R]C(=O)C1=C(O)C(CC=C(C)C)=C(O)C(O)(CC=C(C)C)C1=O</smiles>

\section{Iso- $\alpha$-ácidos (isohumulonas)}<smiles>CC(=O)C1=C(O)C(O)(C(=O)/C=C/C(C)C)C(CC=C(C)C)C1=O</smiles>

A natureza aromática dos lúpulos é devida aos óleos essenciais que constituem cerca de 0,5 a 1,5 $\%$ do peso dos cones. Já foram identificados mais de 200 compostos químicos com aroma, pertencentes às famílias dos compostos sulfurosos, dos terpenos, dos ésteres, dos éteres, dos álcoois, das cetonas e dos ácidos.

\begin{tabular}{lcc}
\hline Composto & $\begin{array}{c}\text { Gama } \\
\text { de concentrações } \\
\text { no Lúpulo }(\% \mathbf{p} / \mathbf{p})\end{array}$ & $\begin{array}{c}\text { Influência no } \\
\text { aroma e gosto } \\
\text { da cerveja }\end{array}$ \\
\hline mirceno & $0,2-0,6$ & \\
pinenos & $0,1-0,3$ & $\begin{array}{c}\text { aromático } \\
\text { sabor } \\
\text { a terpenos }\end{array}$ \\
cariofileno & $0,003-0,005$ & \\
farnasceno & $0,05-0,08$ & \\
humuleno & $0,07-0,1$ & aroma floral \\
\hline ésteres & $0,08-0,15$ & $\begin{array}{c}\text { sabor } \\
\text { oxigenados }\end{array}$ \\
\hline lipidos & $2-4$ & adstringente \\
\hline taninos & $3-5$ &
\end{tabular}

\section{A LEVEDURA}

Só pela acção da levedura se pode transformar o mosto (extracto aquoso do malte e do lúpulo) em cerveja. A alteração fundamental que este microorganismo desencadeia é a metabolização dos tri, di e monossacarídeos e a excreção de

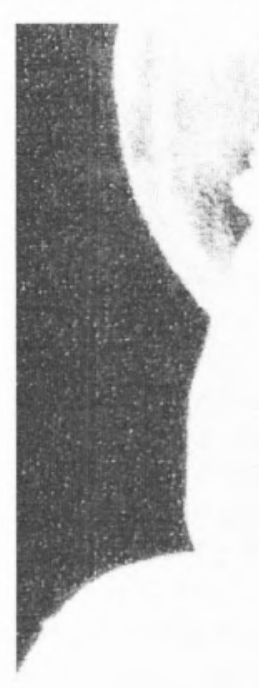

etanol e $\mathrm{CO}_{2}$, que constituem as bases de todo o espectro de aromas e sabores da cerveja.

Os glúcidos assimiláveis pela levedura são convertidos em glucose que é metabolisada pela via glicolítica a piruvato que, por sua vez é convertido em etanol e $\mathrm{CO}_{2}$, tendo como produto intermediário o acetaldeído.
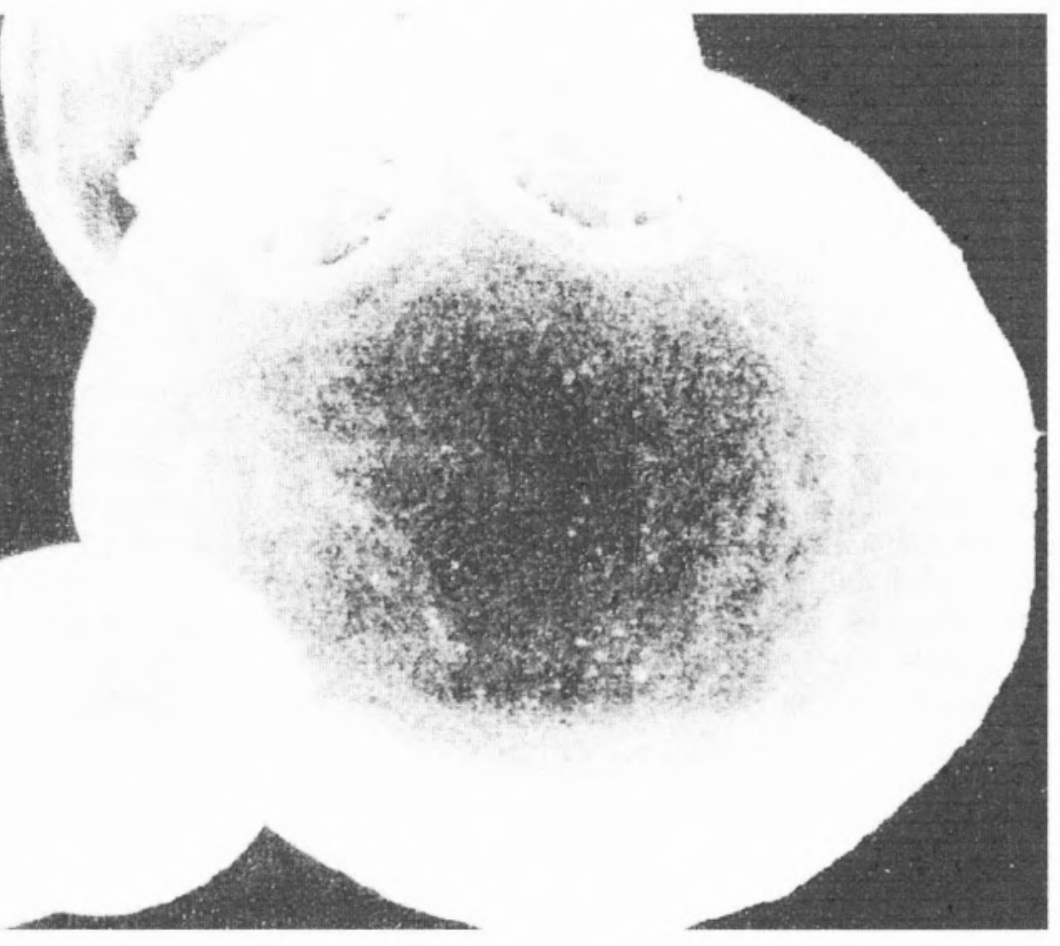

Absorção dos Glúcidos

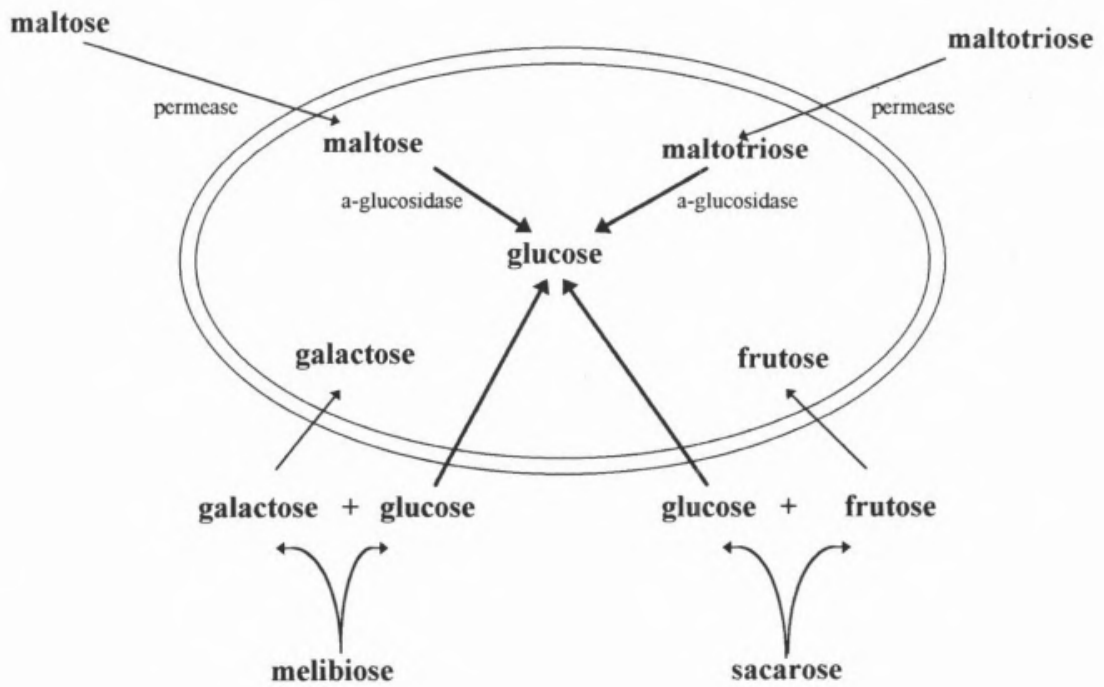




\section{Metabolismo dos Glúcidos \\ Produção de Etanol e $\mathrm{CO}_{2}$}

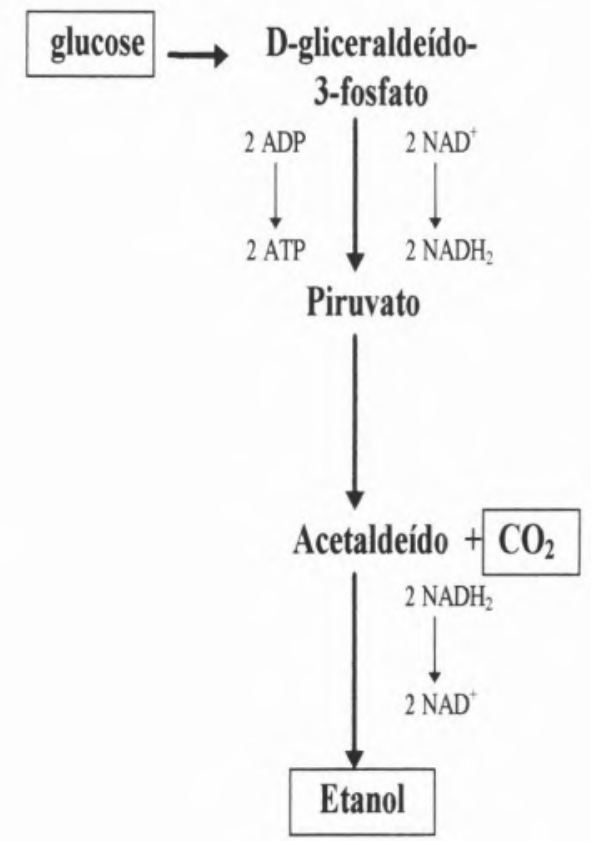

Sendo um organismo vivo, a levedura apresenta uma complexa e intrincada rede de vias metabólicas responsáveis pela degradação de alguns compostos químicos e pela síntese de outros. Estirpes de levedura diferentes produzem quantidades diferentes dos vários compostos, quando fermentam um mosto com características idênticas.

Os compostos produzidos pela levedura pertencem na sua maioria a um dos seguintes grupos químicos:

Álcoois - Para além do etanol existe um grande número de outros álcoois na cerveja. Estes álcoois, vulgarmente designados por álcoois superiores constituem uma parte importante dos produtos formados durante a fermentação. São compostos extremamente aromáticos e têm um papel importante nas características organolépticas da cerveja. A sua formação está relacionada com o metabolismo dos sacarídeos presentes no mosto e com o metabolismo dos aminoácidos, em particular com um

\section{Bioquímica da Formação de Álcoois Superiores}

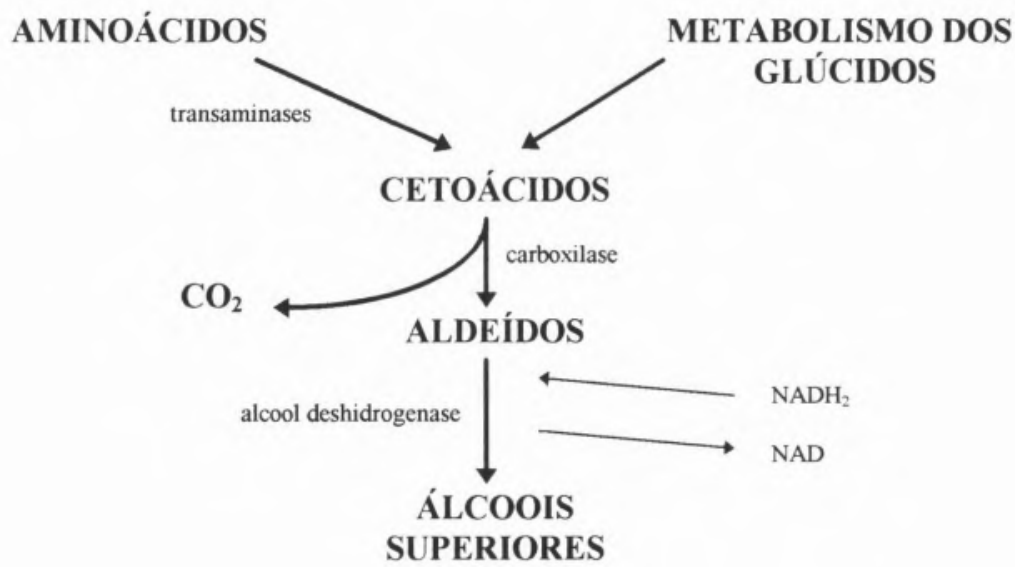

Álcoois Superiores Derivados de Aminoácidos

\begin{tabular}{cc}
\hline Aminoácido & Álcool superior \\
\hline Valina & Isobutanol \\
Treonina & Propanol \\
Isoleucina & 2-Metil-1-butanol \\
Leucina & 3-Metil-1-butanol \\
Fenilalanina & Feniletanol \\
\hline
\end{tabular}

produto intermédio desse metabolismo - os cetoácidos. A estirpe de levedura escolhida para a fermentação é determinante para os níveis finais de álcoois superiores na cerveja.

Ésteres - A maioria dos ésteres encontrados na cerveja resulta do metabolismo da levedura. As reacções de esterificação não enzimáticas são em geral, insignificantes. Estes compostos são, conjuntamente com os álcoois superiores, responsáveis pelo "bouquet" de algumas cervejas. Os esteres são sintetizados a partir de um álcool e de um ácido orgânico da família dos acilCoA (compostos transportadores de grupos acilo, produtos intermédios do metabolismo dos ácidos gordos). A síntese dos ésteres é catalisada pelos enzimas da família das acetilálcool transferases (AAT). O acilCoA mais comum é o acetil-CoA e o alcool mais abundante na cerveja é

\begin{tabular}{lcc}
\hline \multicolumn{1}{c}{ Álcool } & $\begin{array}{c}\text { Concentração } \\
\text { na cerveja }\end{array}$ & $\begin{array}{c}\text { Limiar de } \\
\text { percepção }\end{array}$ \\
\hline n-propanol & $4-60 \mathrm{mg} / \mathrm{l}$ & $800 \mathrm{mg} / \mathrm{l}$ \\
isobutanol & $4-57 \mathrm{mg} / \mathrm{l}$ & $200 \mathrm{mg} / \mathrm{l}$ \\
3-metil-1-butanol & $25-133 \mathrm{mg} / \mathrm{l}$ & $70 \mathrm{mg} / \mathrm{l}$ \\
2-feniletanol & $5-102 \mathrm{mg} / \mathrm{l}$ & $125 \mathrm{mg} / \mathrm{l}$ \\
\hline
\end{tabular}

o etanol. Daí que o éster presente em maior quantidade seja o acetato de etilo que apresenta um aroma a solvente ou verniz. Outro éster com bastante influência no aroma da cerveja é o acetato de isoamilo, que se forma pela esterificação do 3-metilbutanol e do acetil-CoA. Este éster possui um característico aroma a banana, detectado quando os seus níveis ultrapassam o limiar de percepção olfactivo. Embora muitos factores, entre os quais as variáveis do processo fermentativo, afectem a síntese de ésteres, é provavelmente a estirpe de levedura a principal responsável pela formação destes compostos.

\begin{tabular}{|c|c|c|}
\hline Éster & $\begin{array}{c}\text { Concentração } \\
\text { na cerveja }\end{array}$ & $\begin{array}{l}\text { Limiar de } \\
\text { percepção }\end{array}$ \\
\hline Acetato de etilo & $8-48 \mathrm{mg} / \mathrm{l}$ & $33 \mathrm{mg} / \mathrm{l}$ \\
\hline Hexanoato de etilo & $0,1-1,5 \mathrm{mg} / \mathrm{l}$ & $0,23 \mathrm{mg} / \mathrm{l}$ \\
\hline acetato de isoamilo & $0,8-6,6 \mathrm{mg} / \mathrm{l}$ & $1,6 \mathrm{mg} / \mathrm{l}$ \\
\hline acetato de isobutilo & $0,03-0,25 \mathrm{mg} /$ & $4,6 \mathrm{mg} / \mathrm{l}$ \\
\hline
\end{tabular}


Bioquímica da Formação dos Ésteres

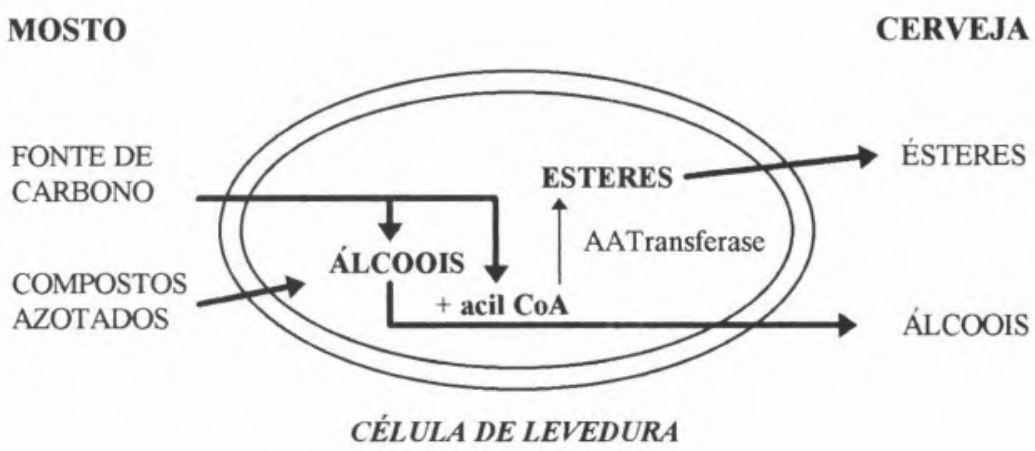
enxofre é um elemento extremamente importante na produção de cerveja pelos compostos que pode formar e que contribuem significativamente para as características organolépticas da bebida. Normalmente os compostos sulfurosos não são desejáveis, embora alguns tipos de cerveja sejam caracterizados por "vestígios" em alguns destes compostos. Dentro deste grupo destacam-se o sulfureto de hidrogénio, o dimetilsulfureto, o dióxido de enxofre e os tióis. Embora quantidades vestigiárias destes compostos sejam aceitáveis ou até desejáveis em alguns tipos de cerveja, quando presentes em excesso, eles podem transmitir-lhe aromas desagradáveis.
Compostos sulfurosos - O

Embora os compostos voláteis de enxofre possam já existir nos lúpulos e nos maltes, é durante a fermentação que a grande maioria se forma. Em condições normais de fermentação, o $\mathrm{CO}_{2}$ formado que se liberta é suficiente para os arrastar para fora da cerveja, à medida que eles se vão formando.

\section{Formação \\ do Dimetilsulfureto - DMS}

\begin{tabular}{cc}
\hline & $\begin{array}{c}\text { Limiar } \\
\text { de percepção }\end{array}$ \\
\hline Dióxido de enxofre & $15-30 \mu \mathrm{g} / \mathrm{l}$ \\
Sulfureto de hidrogénio & $1-5 \mu \mathrm{g} / \mathrm{l}$ \\
Dimetilsulfureto & $20-40 \mu \mathrm{g} /$ \\
3-Metil-2-buteno-1-tiol & $4-35 \mathrm{ng} / \mathrm{l}$ \\
Metanotiol & $0,2-0,5 \mu \mathrm{g} / \mathrm{l}$ \\
\hline
\end{tabular}

Formação do Dimetilsulfureto - DMS

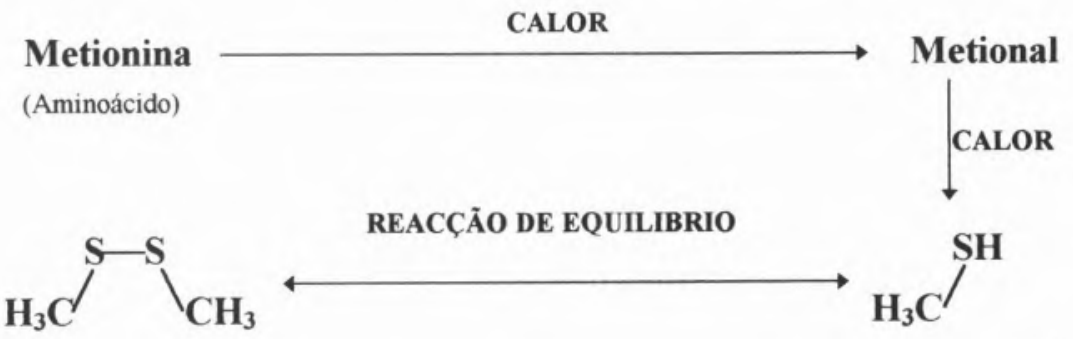

Dimetilsulfureto

Metanotiol
Compostos com grupos carbonilo - A importância destes compostos reside no seu elevado potencial aromático e na influência que têm na estabilidade organoléptica da cerveja ao longo do seu tempo de vida. Quantidades excessivas de compostos carbonilados são características de cervejas "velhas" e oxidadas. O efeito da presença de aldeídos na cerveja pode traduzir-se por um aroma a "palha / erva" como se verifica para o propanal, o 2-metil butanal e o pentanal ou por um gosto a "papel / cartão" como o conferido pelo 2-transnonenal e pelo furfural.

O acetaldeído é o aldeído presente em maior quantidade na cerveja. Este composto forma-se durante a fermentação, e é um produto intermédio na via de síntese do etanol a partir dos sacarídeos do mosto. O acetaldeído formado pode ser reduzido a etanol ou oxidado a ácido acético. Parte do acetaldeído excretado pela levedura pode também ser, no final da fermentação, reabsorvido e reduzido enzimaticamente a etanol. Quando presente em níveis superiores ao limiar de percepção olfactiva, o acetaldeído pode conferir à cerveja um aroma intenso a maçã.

Os compostos 2,3-butanodiona (comumente designado por diacetilo) e a 2,3-pentanodiona introduzem na cerveja um aroma e um gosto descritos muitas vezes como idênticos ao da manteiga de amendoím, do caramelo ou do mel. Nos últimos anos tem havido um grande interesse relativamente aos factores que influenciam a concentração de diacetilo na cerveja bem como às técnicas analíticas para a sua determinação. Estes dois compostos são vulgarmente designados por dicetonas vicinais por apresentarem dois grupos carbonilo adjacentes.

O diacetilo bem como a 2,3pentanodiona são produzidos em grande quantidade nas fases iniciais da fermentação a partir de produtos intermédios do metabolismo dos aminoácidos, respectivamente o $\alpha$ acelactato e o $\alpha$-acetohidroxibutira- 


\section{Bioquímica da formação do Diacetilo na Cerveja}

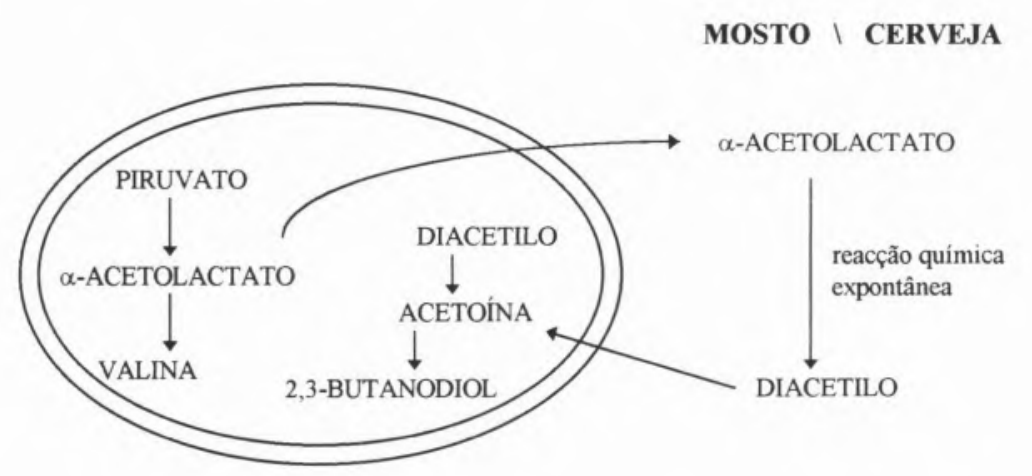

CÉLULA DE LEVEDURA

to, excretados pela levedura. A redução destes compostos às dicetonas respectivas é um processo não enzimático que ocorre no exterior das células. As dicetonas são então reabsorvidas pela levedura e reduzidas enzimaticamente a compostos menos activos do ponto de vista organoléptico.

\section{Influência das Dicetonas Vicinais no Aroma da Cerveja}

\begin{tabular}{lc}
\hline & $\begin{array}{c}\text { Limiar } \\
\text { de percepção }\end{array}$ \\
\hline Diacetilo & $0,15-0,20 \mathrm{mg} / \mathrm{l}$ \\
2,3 -pentanodiona & $1,0 \mathrm{mg} / \mathrm{l}$ \\
\hline
\end{tabular}

\section{AS VARIÁVEIS DO PROCESSO}

\section{BRASSAGEM \\ (PRODUÇÃO DO MOSTO)}

É durante a fase inicial do processo de brassagem que são extraídos do malte os sacarídeos, as proteínas e muitos outros compostos presentes no malte. Tanto os sacarídeos como as proteínas são então hidrolizados enzimaticamente, de uma forma controlada, tornando-os assimiláveis pela levedura. São vários os enzimas responsáveis por estas reacções hidrolíticas (amilases, proteases, peptidases, etc.), cada um dos quais com temperatura e pH óptimos de actuação. O controlo destes dois parâmetros é por isso crucial durante o processo.

Após a extracção e hidrólise, as cascas dos grãos de malte são separadas do mosto, por uma filtração. Na fase final da brassagem, o mosto é levado à ebulição para inactivar todos os enzimas e precipitar algumas proteínas de elevada massa molecular que poderiam precipitar posteriormente na cerveja turvando-a.

É também durante a ebulição que são extraídos e isomerizados os ácidos alfa do lúpulo. Também este processo é muito dependente do $\mathrm{pH}$. temperatura e tempo.

Após a ebulição, o mosto é clarificado num processo onde são removidos todos os colóides precipitados, constituidos essencialmente por proteínas e alguns lípidos. A quantidade de sólidos suspensos no mosto ("trub"), que passa para a fermentação tem efeitos determinantes no aroma da cerveja produzida. Ao promover a multiplicação celular, o "trub" altera os padrões da fermenta- ção. Produzem-se mais compostos sulfurosos e mais compostos precursores de reacções oxidativas que aceleram o processo de envelhecimento da cerveja.

\section{FERMENTACÃO}

Foi já referido que as principais características organolépticas da cerveja derivam do metabolismo da levedura durante o processo fermentativo. Consequentemente, a composição do mosto e os parâmetros do processo que afectam o desempenho fermentativo da levedura afectam também a qualidade da cerveja. Estes factores estão interrelacionados e torna-se dificil caracterizar a influência que cada um deles exerce isoladamente no perfil sensorial (organoléptico) do produto final.

A Estirpe levuriana contribui de forma significativa para o carácter mais ou menos aromático da cerveja. Cada estirpe comporta-se de forma diferente para um dado conjunto de condições de fermentação. O técnico cervejeiro tem que ter em consideração o perfíl aromático produzido por cada estirpe (compostos sulfurosos, ésteres, álcoois, etc.), quando faz a selecção da levedura a utilizar na produção de cerveja.

Variações na quantidade de células de levedura presente no inicio da fermentação, taxa de inoculação, traduzem-se em diferentes padrões de crescimento, com influência directa no aroma da cerveja alterando as proporções relativas de compostos voláteis. Um crescimento controlado em cada fermentação é uma das principais preocupações do cervejeiro, pois só assim se consegue garantir uma regularidade nas características do produto.

A temperatura influencia quantitativamente cada reacção bio-

\begin{tabular}{cccc}
\hline Enzima & Substrato & pH Óptimo & Temperatura \\
\hline$\alpha$ - Amilase & Amido & $5,5-6,0$ & $55-65{ }^{\circ} \mathrm{C}$ \\
$\beta$ - Amilase & Amido & $4,0-6,0$ & $45-55^{\circ} \mathrm{C}$ \\
Proteases & Proteínas & $4,0-5,0$ & $<50{ }^{\circ} \mathrm{C}$ \\
Peptidases & Peptidos & $4,2-5,0$ & $<55^{\circ} \mathrm{C}$ \\
\hline
\end{tabular}


química do metabolismo da levedura. Temperaturas mais altas acentuam a velocidade de fermentação, a produção de álcoois e promovem a conversão extracelular dos precursores das dicetonas vicinais.

O oxigénio dissolvido e o teor em ácidos gordos saturados e insaturados no mosto no inicio da fermentação influencia a actividade metabólica das células da levedura, uma vez que o oxigénio é essencial para a formação de compostos que participam na formação de novas células. O controlo da quantidade de oxigénio dissolvido é importante para o crescimento uniforme da levedura e para a produção consistente de compostos organolepticamente activos.

A geometria dos fermentadores tem também um papel importante na fermentação, devido aos efeitos que a pressão hidrostática exerce sobre a quantidade de $\mathrm{CO}_{2}$, que permanece em solução e sobre as correntes de convexão que se geram durante a fermentação. A taxa de crescimento da levedura e a produção de compostos aromáticos decrescem sob as concentrações elevadas de $\mathrm{CO}_{2}$ dissolvido que existem em tanques de geometria cilindrica vertical. As diferenças que existem nas caracteristicas da fermentação entre tanques verticais e horizontais resultam de diferenças na agitação natural provocada pela libertação do $\mathrm{CO}_{2}$ formado. Na prática os tanques verticais não devem ter uma altura superior a duas vezes o diametro.

\section{MATURAC ÃO}

A Maturação da cerveja diz respeito fundamentalmente ao "fixar" das características organolépticas da bebida e à sua estabilização física (coloidal). No final da fermentação, existem na cerveja "jovem" muitos sabores e aromas que devem ser eliminados ou corrigidos. O processo de maturação reduz os níveis destes compostos produzindo um aroma e um sabor "mais limpos".
A maturação é normalmente levada a cabo após a remoção da maior parte da levedura no final da fermentação, com o arrefecimento da cerveja até temperaturas próximas dos $0^{\circ} \mathrm{C}$ e a permanência a essa temperatura durante um período mais ou menos longo. Durante esta fase, as células de levedura que permanecem em contacto com a cerveja reabsorvem as dicetonas vicinais e convertem-nas enzimaticamente em compostos que não apresentam actividade organoléptica. A continua libertaçāo de $\mathrm{CO}_{2}$ durante a maturação, embora menos acentuada contribui também para eliminar o excesso de alguns compostos voláteis indesejados.

\section{FILTRACÃO IEMBALAGEM}

Após a maturação é necessário que a cerveja seja filtrada para que se obtenha no final uma bebida com uma limpidez e um brilho cristalinos. Durante esta fase do processo são feitos alguns ajustes nos níveis de $\mathrm{CO}_{2}$ dissolvido (carbonatação), tão característico na cerveja e desejado pelos consumidores.

Na última fase de produção é feito o acondicionamento. Este pode ser feito em latas, garrafas ou barris e não é menos importante do que qualquer uma das fases anteriores do processo. Mesmo depois de acondicionada, a cerveja continua a ser alvo de transformações químicas que podem em casos extremos levar à deterioração do aroma e gosto bem como ao aparecimento de turvação. A maioria das alterações que levam ao envelhecimento da cerveja dentro da respectiva embalagem são devidas a processos de oxidação química, que envolvem álcoois superiores e melanoidinas. Os níveis de oxigénio dissolvido na cerveja embalada são determinantes para a sua estabilidade organoléptica e física. O oxigénio desencadeia a formação de compostos altamente reactivos que levam não só ao aparecimento de aldeídos como à formação de complexos entre proteínas e po- lifenóis que precipitam e turvam a cerveja. Também a cor da cerveja aumenta com o tempo em consequência de reacções de oxidação dos taninos. A cor do vidro das garrafas protege a bebida dos efeitos da luz que, em determinados comprimentos de onda, desencadeia também algumas reacções que levam à degradação da bebida. Por forma a aumentar a estabilidade da bebida, o cervejeiro tem como principal preocupação, durante o acondicionamento, manter os níveis de oxigénio dissolvido tão baixos quanto possível. Consegue-se assim que a cerveja chegue até aos consumidores com o gosto e o aroma frescos que a caracterizam.

Apenas foram focados neste trabalho alguns dos aspectos mais importantes do processo cervejeiro, com o objectivo de explicar as bases químicas subjacentes às características desta bebida, clarificando as várias fases de um processo complexo e fascinante em relação ao qual o conhecimento está constantemente a evoluir e provavelmente um dos que envolvem hoje em dia mais investigação.

\section{AGRADECIMENTOS}

Agradeço à CENTRAL DE CERVEJAS,S,A. a autorização para publicação deste trabalho.

\footnotetext{
* Central de Cervejas, S.A.

Estrada de Alfarrobeira, Apartado 15 2626 Vialonga
}

\section{BIBLIOGRAFIA}

C.W.Bamforth, et.al., ASBC Journal, 51 (1993) 79.

J., Stead, The Brewer, September, 1996, 389-400.

D. E., Briggs, et. al., Malting and Brewing Science, Chapman and Hall.

W.A., Hardwick, Hanbook of Brewing, Marcel Dekker, Inc. 